\title{
Lipid Profile Evaluation in Second and Third Trimester of Pregnancy and Fetomaternal Outcome
}

\author{
Nirmala Sharma ${ }^{1}$, Jaswant Raj ${ }^{2}$, Neha Seehra*3 \\ 1. MBBS, MS, Department of Obstetrics and Gynecology, Senior Professor, Head of Department and Unit Head. Government Medical College, \\ Kota, Rajasthan, India. \\ 2. MBBS, Department of Obstetrics and Gynecology, Postgraduate Student, Government Medical College, Kota, Rajasthan, India. \\ 3. MBBS, MS, DNB, Department of Obstetrics and Gynecology, Assistant Professor, Government Medical College, Kota, Rajasthan, India. \\ *Corresponding author's E-mail: dr.nehaseehra@gmail.com
}

Received: 21-04-2021; Revised: 23-06-2021; Accepted: 29-06-2021; Published on: 15-07-2021.

\section{ABSTRACT}

Increase in maternal cholesterol levels are thought to be an adaptive change necessary for proper fetal development and growth. However maternal dyslipedemia has been shown to be associated with complications during pregnancy. Objective of this study is evaluation of changes in lipid profile during pregnancy and their association with fetomaternal outcome. It was a prospective descriptive study conducted over 200 pregnant women from December 2018 to August 2020 at jay kaylon hospital, kota, Rajasthan. $3 \mathrm{ml}$ serum samples of enrolled pregnant women and 100 non pregnant women were obtained for the estimation of serum lipid profile by ERBA manheim EM360 auto analyzer. $56 \%$ women belonged to the age group of $21-25$ years, $70 \%$ patients were from urban population, $63.5 \%$ women had vegetarian diet, $49.5 \%$ were primigravida. Statistically significant rise found in the lipid profile values $(p<0.001)$ during pregnancy when compared to non-pregnant women. $25 \%$ pregnant women developed gestational hypertension, $5 \%$ patients developed preeclampsia, $69.5 \%$ women delivered vaginally while $30.5 \%$ by cesarean section. 27 fetus failed to achieve birth weight of $>2.5$ kilogram. Pregnancy furnishes a unique opportunity for detection of subclinical dyslipidemia, significant increase has been found in the lipid profile when compared to non-pregnant women. However higher lipid levels have shown to be associated with gestational hypertension, preeclampsia and their complications along with low birth weight. Hence, we recommend lipid profile evaluation should be a part of routine antenatal investigations for early detection and management of these complications.

Keywords: Dyslipidemia, gestational hypertension, lipid profile.

QUICK RESPONSE CODE $\rightarrow$

DOI:

10.47583/ijpsrr.2021.v69i01.017

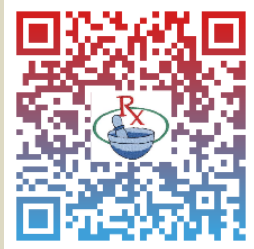

DOI link: http://dx.doi.org/10.47583/ijpsrr.2021.v69i01.017

\section{INTRODUCTION}

$\mathrm{M}$ aternal dyslipidemia recognized as a physiological phenomenon essential to provide fuel and nutrition to the growing fetus. Women body undergoes various types of physiological, biochemical and hormonal changes during pregnancy to meet the increased demand of fetus, to maintain metabolism and regulation of the complementary maternal system. As pregnancy advances, there is increased demand of energy for growing fetus; pregnant women require an additional energy of $300 \mathrm{Kcal} /$ day over routine energy intake ${ }^{1}$. Physiologically lipid metabolism greatly changes during pregnancy, ${ }^{2,3}$ but the way in which these changes affect lipid deposition in the adipose tissue of the fetus and its subsequent growth is not completely understood. The availability of substrate for the fetus depends on their concentration in the maternal circulation and to the extent they are transported across the placenta. Thus, maternal hyperlipidemia during pregnancy facilitates the availability of lipids to fetus and could also contribute to its accumulation in fat depots. Maternal accumulation of fat depots and hyperlipidemia are the two principle changes in the lipid metabolism that occurred during pregnancy ${ }^{4,5}$. During first two trimesters, lipid metabolism is ' primarily anabolic', maternal hyperphagia increases the availability of substrates, which together with higher insulin levels and enhanced insulin sensitivity ${ }^{6,7}$ during early pregnancy resulting in enhanced lipogenesis apart from increased activity of adipose tissue lipoprotein lipase $^{8}$.

In early pregnancy, there is an increase intake of the diet and increase synthesis of lipids which leads to accumulation of extra body fat. Various fractions of lipids include Total Cholesterol (TC), Triacylglycerol (formerly known as triglyceride), High density lipoprotein (HDL), low density lipoprotein (LDL-C), Very low-density lipoprotein (VLDL). In later stage of pregnancy, there is accelerated fat breakdown which plays an important role in the fetal development. The energy provided by lipid is used in cellular proliferation of uterus, blood volume expansion of mother, implantation of fetus in uterus, uteroplacental and fetal development. There are physiological hyper plastic changes in pancreatic beta cells that results in an increase in the insulin hormone levels in blood? Hyperinsulinemia leads to an increase in peripheral glucose utilization, a decline in fasting plasma glucose levels, increased tissue storage of glycogen, increased glycogen accumulation in the liver as well as increased 
storage of lipids and decreased lipid breakdown, increased storage of fats and decreased lipolysis. Due to insulin resistance in pregnancy, there is more utilization of fats than carbohydrates for energy by mother and carbohydrates are spared for fetus, thus it's a physiological adaptation of the mother to ensure adequate carbohydrate supply for rapidly growing fetus ${ }^{10}$. Oxidative stress is present in normal pregnancy ${ }^{11,12}$ and could be the result of maternal hyperlipidemia increments of oxidative stress indices over control values have been associated with altered pregnancy outcome, as has been shown in diabetes $^{13,14}$, pre-eclampsia ${ }^{15},{ }^{16}$ and fetal growth restriction ${ }^{17}$. Looking over lipid profile at a single point of time in pregnancy may not be able to determine the elevation from baseline; hence with the lipid profile estimation at two points of time during pregnancy, we tried to study the rate of change of maternal cholesterol, LDL, HDL, VLDL levels and their implications over fetomaternal outcome. In our study we compared and analyze the change in the lipid profile in pregnant women versus non pregnant women, and how this changed profile affects the outcome of pregnancy.

\section{MATERIAL AND METHODS}

The present study was a descriptive study, conducted prospectively in the department of obstetrics and gynaecology, jay kay lon Hospital, Government medical college, Kota, Rajasthan, during the period of December 2018 to August 2020. We enrolled 200 pregnant women who came for antenatal check up in our antenatal clinic beyond 13 weeks of gestation in second trimester.

\section{Study design}

Prospective descriptive study

\section{Study location}

Department of obstetrics and gynaecology, jay kay lon Hospital, Government medical college, Kota, Rajasthan.

\section{Study duration}

December 2018 to August 2020

\section{Sample size}

\section{0 pregnant women}

\section{Subject and selection method}

We enrolled 200 pregnant women who came for antenatal checkup in our antenatal clinic beyond 13 weeks of gestation in second trimester.

\section{Inclusion criteria}

Women $\geq 18$ years old, Singleton pregnancy with period of gestation beyond 13 weeks.

\section{Exclusion criteria}

Pregnant women with diagnosed medical disorders like chronic hypertension, diabetes mellitus, renal disorder, epilepsy, psychotic or neurological disorders.

\section{Procedure methodology}

All eligible participants were enrolled for the study after obtaining an informed written consent. After enrolment two serum samples were drawn at two points of times during pregnancy, first serum specimen was collected at the time of enrollment during 13-27 week of gestation; the second sample was collected at 28-40 week of gestation during follow up visits. Serum sample of 100 Non pregnant, healthy women of same age group were taken as control to compare the lipid profile values. Under aseptic precautions, $3 \mathrm{ml}$ intravenous sample taken from antecubital veinand samples were sent to the central laboratory of the medical college, Kota, Rajasthan. Serum separated by centrifugation of samples and processed for the estimation of serum lipid profile. Chemical analysis was done by ERBA manheim EM 360 auto analyzer.(Figure 1)

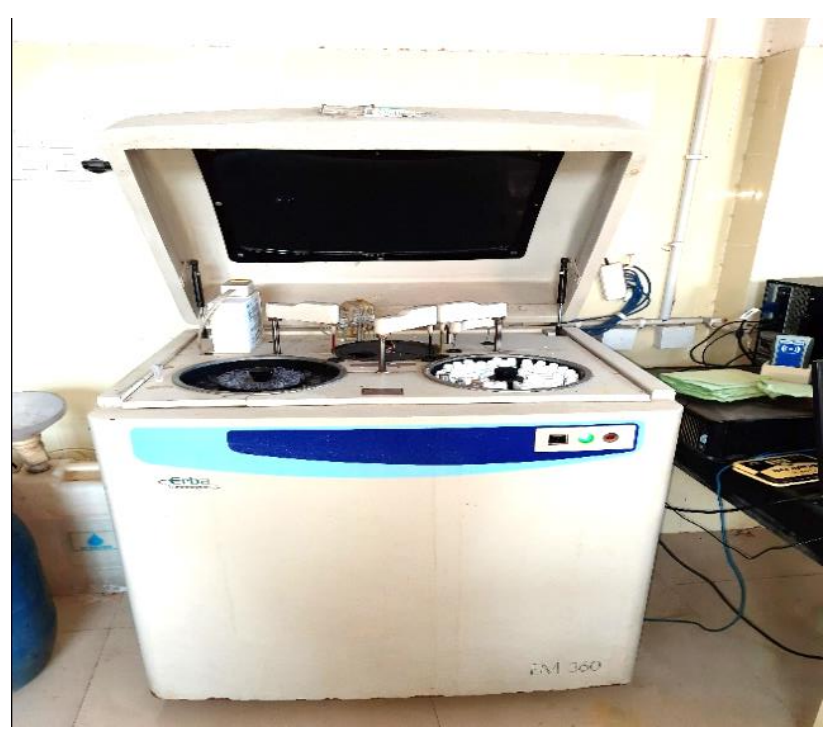

Figure 1: ERBA manheim EM 360 auto analyzer.

\section{Statistical analysis}

Reported data were collected and entered in MS excel sheet, Linear variables were summarized as mean and standard deviation and analyzed by using paired and unpaired student's t test. Nominal or categorical variables were presented as proportions. $P$ value $<0.05$ was taken as significant. Statistical analysis performed using Medcalc 16.4 version software.

This work was approved by the ethical committee of government medical college, Kota, Rajasthan.

\section{RESULTS AND DISCUSSION}

We observed 200 eligible pregnant women to document the changes in lipid profile during second and third trimesters. Following were the main results.56\% of our studied women belonged to the age group of 21-25 years $.70 \%$ of women were residing in urban area whereas $30 \%$ belonged to rural area. Majority of our studied women i.e $63.5 \%$ were vegetarian and $36.5 \%$ were non vegetarian. (Table no. 1) 
Table 1: Demographical variables

\begin{tabular}{|c|c|c|}
\hline Age (years) & Frequency & Percentage \\
\hline$\leq 20$ & 22 & 11.0 \\
\hline $21-25$ & 112 & 56.0 \\
\hline $26-30$ & 48 & 24.0 \\
\hline$>30$ & 18 & 9.0 \\
\hline RESIDENTIAL & & \\
\hline DISTRIBUTION- & & 30 \\
\hline Rural & 60 & 70 \\
\hline Urban & 140 & \\
\hline DIET - & & 36.5 \\
\hline non-vegetarian diet & 73 & 63.5 \\
\hline
\end{tabular}

In our study population $49.5 \%$ of women were primigravida, $27 \%$ were Gravida 2 while rest were gravida 3 and more (table no.2).
Table 2: Obstetrical parameter

\begin{tabular}{|c|c|c|}
\hline Gravid & Number & Percentage \\
\hline G1 & 99 & 49.5 \\
\hline G2 & 54 & 27.0 \\
\hline G3 & 38 & 19.0 \\
\hline G4 & 09 & 4.5 \\
\hline Total & 200 & 100 \\
\hline
\end{tabular}

When we compared the lipid profile values in non pregnant versus pregnant women, all the five parameters increased during pregnancy. The percentage increase between non pregnant women and second trimester of pregnant women were as follows- TC-41.4\%, TG- $45.3 \%$, HDL- 16.2\%, LDL- 57.4\%, VLDL-45.3\%. The percentage increase between non pregnant women and third trimester of pregnancy was even higher as follows- TC65.7\%, TG- 92.8\%, HDL-25.9\%, LDL- 86.8\%, VLDL- $92.8 \%$. The percentage increase between second and third trimester in pregnancy also found to be raised with a statistically significant difference $(p<0.001)$. (Table no. 3 )

Table 3: Lipid profile values in non pregnant women

\begin{tabular}{|c|c|c|c|c|c|c|}
\hline Lipid profile & N & Mean & SD & Median & Minimum & Maximum \\
\hline S. cholesterol & 100 & 151.88 & 25.84 & 149 & 116 & 202 \\
\hline HDL & 100 & 55.63 & 5.20 & 54.5 & 44 & 67 \\
\hline TG & 100 & 117.89 & 29.03 & 124 & 80 & 200 \\
\hline LDL & 100 & 72.64 & 23.23 & 76.5 & 43 & 120 \\
\hline VLDL & 100 & 23.61 & 5.89 & 25 & 16 & 40 \\
\hline
\end{tabular}

Lipid profile values in $2^{\text {nd }}$ and $3^{\text {rd }}$ trimester of pregnancy-

\begin{tabular}{|c|c|c|c|c|c|c|c|c|}
\hline Lipid profile & trimester & $\mathbf{N}$ & Mean & SD & Median & Min & Max & 'p' value \\
\hline \multirow{2}{*}{ S. cholesterol } & II & 200 & 214.37 & 38.34 & 212 & 143 & 352 & \multirow{2}{*}{$<0.001$} \\
\hline & III & 200 & 250.91 & 43.76 & 249 & 159 & 399 & \\
\hline \multirow{2}{*}{$\mathrm{HDL}$} & II & 200 & 64.62 & 12.12 & 63.5 & 40 & 90 & \multirow{2}{*}{$<0.001$} \\
\hline & III & 200 & 70.01 & 11.55 & 70 & 45 & 94 & \\
\hline \multirow{2}{*}{ TG } & II & 200 & 171.43 & 62.89 & 155 & 64 & 349 & \multirow{2}{*}{$<0.001$} \\
\hline & III & 200 & 227.51 & 74.28 & 202 & 72 & 399 & \\
\hline \multirow{2}{*}{ LDL } & II & 200 & 114.40 & 35.84 & 111 & 43.2 & 237.4 & \multirow{2}{*}{$<0.001$} \\
\hline & III & 200 & 135.81 & 39.93 & 132.8 & 42.6 & 280 & \\
\hline \multirow{2}{*}{ VLDL } & II & 200 & 34.29 & 12.58 & 31 & 12.8 & 69.8 & \multirow{2}{*}{$<0.001$} \\
\hline & III & 200 & 45.50 & 14.86 & 40.4 & 14.4 & 79.8 & \\
\hline
\end{tabular}

67.5\% patients delivered without any maternal complications. Among 200 studied patients, 31\%patients were diagnosed with hypertensive disorders of pregnancy, $25 \%$ patients had gestational hypertension and $5 \%$ patients had severe pre-eclampsia. When we compared the mean of each lipid profile parameters between normotensive and hypertensive groups, statistically significant differences noted in total cholesterol, triacylglycerol, low density lipoprotein, very low density lipoprotein levels.(Table no. 4) 
Table 4: Comparison of percentage increase in the lipid profile parameters with respect to gestational hypertension.

\begin{tabular}{|c|c|c|c|c|c|c|c|c|c|c|}
\hline & \multicolumn{2}{|c|}{ Population ( $N=\mathbf{2 0 0})$} & \multirow[b]{2}{*}{ Trimesters } & \multicolumn{2}{|c|}{ Mean } & \multicolumn{2}{|c|}{ Median } & \multicolumn{2}{|c|}{ SD } & \multirow[t]{2}{*}{ P value } \\
\hline & $\begin{array}{c}\text { Normot } \\
\text { ensive }\end{array}$ & $\begin{array}{l}\text { hyperten } \\
\text { sive }\end{array}$ & & $\begin{array}{l}\text { Normot } \\
\text { ensive }\end{array}$ & $\begin{array}{l}\text { hyperte } \\
\text { nsive }\end{array}$ & $\begin{array}{l}\text { Normot } \\
\text { ensive }\end{array}$ & $\begin{array}{l}\text { hyperte } \\
\text { nsive }\end{array}$ & $\begin{array}{c}\text { Normot } \\
\text { ensive }\end{array}$ & $\begin{array}{l}\text { hyperte } \\
\text { nsive }\end{array}$ & \\
\hline \multirow{2}{*}{ TC } & \multirow{2}{*}{138} & \multirow{2}{*}{62} & II & 200.5 & 245.2 & 197.5 & 250 & 30.3 & 36.6 & \multirow{2}{*}{$<0.0001$} \\
\hline & & & III & 236 & 284 & 234 & 284 & 31.8 & 48.6 & \\
\hline \multirow{2}{*}{ TG } & \multirow{2}{*}{138} & \multirow{2}{*}{62} & II & 157.9 & 201.6 & 150 & 206.5 & 60.3 & 58.2 & \multirow{2}{*}{$<0.0006$} \\
\hline & & & III & 215.6 & 254 & 195 & 255 & 72.4 & 72.1 & \\
\hline \multirow{2}{*}{ HDL } & \multirow{2}{*}{138} & \multirow{2}{*}{62} & ॥ & 64.6 & 64.6 & 65 & 60 & 12.2 & 12 & \multirow{2}{*}{0.12} \\
\hline & & & III & 69.2 & 71.9 & 69 & 72 & 11.3 & 12 & \\
\hline \multirow{2}{*}{ LDL } & \multirow{2}{*}{138} & \multirow{2}{*}{62} & II & 102.8 & 140.2 & 101.6 & 139.2 & 29.3 & 43.2 & \multirow{2}{*}{$<0.0001$} \\
\hline & & & III & 124.4 & 161.3 & 124.9 & 157.6 & 33.5 & 41.4 & \\
\hline \multirow{2}{*}{ VLDL } & \multirow{2}{*}{138} & \multirow{2}{*}{62} & II & 31.6 & 40.3 & 30 & 41.3 & 12.1 & 11.6 & \multirow{2}{*}{$<0.0006$} \\
\hline & & & III & 43.1 & 50.8 & 39 & 51 & 14.5 & 14.4 & \\
\hline
\end{tabular}

When we compared the observed fetal weight and change in the lipid profile, there was no significant association found in the percentage increase in lipid profile with the fetal birth weight in study population. However, when we compared the mean of each lipid parameters in $3^{\text {rd }}$ trimester among patients delivered with Normal birth weight versus low birth weight neonates, statistically significant difference was found in TC, VLDL ( $p$ value $<0.005$ ) levels and low birth weight.(Table no. 5)

Table 5: Changes in the lipid profile with respect to the observed fetal birth weight.

\begin{tabular}{|c|c|c|c|c|c|c|c|c|}
\hline Lipid profile & Birth weight & N & Mean & SD & Median & Min. & Max. & 'p' value \\
\hline \multirow{2}{*}{ S. cholesterol } & LBW & 27 & 266 & 47.4 & 261 & 189 & 396 & 0.054 \\
\cline { 2 - 4 } & NBW & 173 & 248.6 & 42.8 & 245 & 159 & 399 & \\
\hline \multirow{2}{*}{ HDL } & LBW & 27 & 70.5 & 12.1 & 68 & 50 & 90 & 0.82 \\
& NBW & 173 & 69 & 11.5 & 70 & 45 & 94 & \\
\hline \multirow{2}{*}{ TG } & LBW & 27 & 266.1 & 87.5 & 252 & 122 & 399 & 0.003 \\
\hline \multirow{2}{*}{ LDL } & NBW & 173 & 221 & 70.4 & 199 & 72 & 397 & \\
& LBW & 27 & 143.0 & 39.7 & 145 & 65.2 & 235.8 & 0.31 \\
\hline \multirow{2}{*}{ VLDL } & NBW & 173 & 134.7 & 40 & 131.8 & 42.6 & 280 & \\
& LBW & 27 & 53.2 & 17.5 & 50.4 & 24.4 & 79.8 & 0.003 \\
\hline
\end{tabular}

Although increase in maternal cholesterol levels are thought to be an adaptive change necessary for proper fetal development and growth, adverse health outcomes for the mother and fetus have been associated with elevated maternal cholesterol during pregnancy. The most dramatic change observed among the lipid profile was serum hyper triglyceridemia, which may be as high as two to three folds in the third trimester over the levels in non pregnant women.

In our study we observed the same change, total cholesterol, triglyceride, HDL, LDL of the pregnant women in the second and third trimester were found to be higher than those of non pregnant women. This resembles the study done by Wald and Guckle ${ }^{18}$ concluding that increase in the maternal lipid profile is in response to the maternal switch from carbohydrate to fat metabolism which is an alternative pathway for energy generation due to high energy demand. We observed a significant increase in the total cholesterol, triglyceride, HDL, LDL and VLDL levels during third trimester as compared to the second trimester. When we gathered the data on the basis of maternal age, area of residence, and diet, our study didn't find any significant association with the changed lipid profile and above parameters. In our studied pregnant women, women with $\mathrm{BMI} \geq 25$, total cholesterol increased by $23.07 \%$ from second to third trimester, while an increase of $16.61 \%$ was observed in the women with $\mathrm{BMI} \leq$ 25 . For $\mathrm{LDL}$, a $42.06 \%$ increase was observed in $\mathrm{BMI} \geq 25$ against an increase of $19.51 \%$ in normal weight group, however no statistical difference was found between BMI and HDL, TG and VLDL values.

In our study we found strong statistical association between dyslipidemia and development of hypertensive disorders of pregnancy. Mean of four analytes i.e TC, TG, 
LDL, VLDL found highly statistically significant in hypertensive group over normotensive group $(p<0.001)$ except the changes observed in HDL levels were insignificant. Those pregnant women with increased levels of triglycerides in second and third trimester (>250 mg/dl), the probabilities of developing pre-eclampsia were found to be significant. Our findings were also supported by the results of study done by Singh et $\mathrm{al}^{111}$, they found that the mean serum level of total cholesterol (TC), triglycerides (TG), low density lipoprotein cholesterol (LDL-C) and very low density lipoprotein cholesterol (VLDL-C) was significantly higher in women with pre eclampsia as compared to normotensive pregnant women, concluding that the measurement of serum lipid profile in early pregnancy may serve as early predictor of preeclampsia. Women with severe dyslipidemia developed fetal complications of severe fetal growth restriction and intrauterine fetal deaths in their late second and early third trimester. In our study 18 fetus failed to achieve birth weight of $>2.5$ kilogram, there was no association found in the percentage increase of

lipid profile and fetal birth weight. However when we compared the mean values of lipid profile between low birth weight and normal birth weight group, we found an association between TG and VLDL levels with a $p$ value of $<0.05$.Amit D sonagra et $\mathrm{al}^{20}$ in 2017 conducted a study titled study of serum lipid profile in normal pregnancy and found that the mean level of serum triglycerides and total cholesterol were significantly higher and mean level of serum HDL were significantly lower in second and third trimester of pregnancy when compared with healthy non pregnant controls. The mean level of serum LDL was significantly higher in third trimester of pregnancy when compared with controls. They found that as pregnancy advances so does the dyslipidemia, however such changes are more marked in third trimester than second and first trimester.

\section{CONCLUSION}

Pregnancy furnishes a unique opportunity for the detection of subclinical dyslipidemia. Normal gestation is characterized by increase in the lipid production to nurture the healthy fetus. Significant increase has been found in the lipid profile during pregnancy when we compared it against non pregnant state. Elevated physiological lipid profile is essential for maintaining the pregnancy and optimal fetal development but we also found that higher lipid levels may result in adverse fetomaternal outcomes in terms of hypertensive disorders like gestational hypertension, preeclampsia and their complications as well as low birth weight at birth. Thus evaluating dyslipidemia in $2^{\text {nd }}$ and $3^{\text {rd }}$ trimester may help in early prediction and management of these complications. Hence, we recommend that evaluation of lipid profile should be a part of routine antenatal investigations during pregnancy.
Acknowledgment: We would like to thank all of our study participants who gave their consent to enroll in our study and provide the valuable information.

Financial support and Sponsorship - No funding / Sponsorship granted

Conflict of interest- None

\section{REFERENCES}

1. Sivan E, Homko CJ, Chen X, reece EA,Boden G. Effect of insulin on fat metabolism during and after normal pregnancy. Diabetes.1999 apr, 48(4): 8348.PMID:10102701.

2. Alvarej JJ, Montelongo A, IglesiasA, Lasuncion MA,Herrera $\mathrm{E}$; longitudinal study on lipoprotein profile, high density lipoprotein subclass and postheparin lipases during gestation in women.j.Lipid res.1996; 37(2): 299-308

3. Montelongo A, Lasuncion MA, Pallardo LF, Herrera E; longitudinal study of plasma lipoprotein and hormones during pregnancy in normal and diabetic women.Diabetes1992Dec; 41(12): 1651-1659.

4. Hytten FE, Leitch I; component of weight gain .The product for conception. The physiology of human pregnancy .Blackwell scientific publisher, Oxford.UK 1971.

5. Murphy SP, Abrams BF:Changes in energy intake during pregnancy and lactation in a national sample of US women. Am j. public health 1993; 83(8): 1161-1163.

6. Jovanovic L, Metzer BE, Knopp RH, E park, Lee Y J, ,Simpson $\mathrm{JL}$,Homes $\mathrm{L}$. The diabetes in early pregnancy study:bHydroxubutyrate levels in type -1 diabetic pregnancy compared with normal pregnancy.NICHD-Diabetes in early pregnancy study group(DIEP).Diabetes care1998; 21(11): 1978-1984.

7. Buch L, Hornnes PJ, Kuhl C: glucose tolerance in early pregnancy. Acta Endocrinol1986; 112(2): 263-266.

8. Herrera E,Lasumcion MA, Martin A, Zorzano A:Carbohydrate -lipid interactions in pregnancy. in: perinatal biochemistry. CRC Press, Boca Raton 1992; 1-18.

9. Berj JM, Tymoczko JL, Stryer L.Biochemistry. Triacylglycerols are highlyconcentrated energy stores.5th edition, New York: W H Freeman.

10. Chauffard A,Laroche G, Grigaut A.blood lipids in pregnancy.Obstetriqie.1911; 4: 481-2.

11. Arikan S, Konukoglu D, Arikan C, Ackay T, Davas I:Lipid peroxidation and antioxidant status in maternal and cord blood. gynecol obstet. invest. 2001; 51(3): 145-149.

12. Morris JM, Gopaul NK, Endresen MJ, Knight M, Linton EA, Dhir $S$ et al Circulating markers of oxidative stress are raised in normal pregnancy and preeclampsia.Br .j. obstet gynecol.1998; 105(11): 1195-1199.

13. Peuchant $E$, Brun JL, Rigalleau, Dubourg L, ThomasMJ, Daniel JY, Leng JJ, Gin H.oxidative and antioxidative status in pregnant women with either gestational or type 1 diabetes.clin. Biochem.2004Apr; 37(4): 293-8.

14. Evers IM, de Valk HW, Mol Bw, ter Braak EW, Visser GH. Macrosomia despite good glycemic control in type 1 
diabetic pregnancy; results of a nationwide study in the Netherlands.Diabetologia. 2002Nov; 45(11): 1484-9.

15. Egberts J.circulating markers of oxidative stress are raised in normal pregnancy and pre eclampsia.br.J.obstet Gynaecol.1999 Jul; 106(7): 751. PMID:10428540.

16. Poston L, chappell LC . is oxidative stress involved in the aetiology of preeclampsia? Acta Paediatr.Suppl.2001; 90(436): 3-5.

17. Takagi Y, Nikaido T, Toki T et al; levels of oxidative stress and redox related molecules in the placenta in preeclampsia and fetal growth restriction. Virchows Arch.2004; 444(1): 49-55.

18. Wald N, Guckle H.comparative study of lipid profile of normal pregnant women in the different trimester.Br. med. J .1988; 297: 883-887.

19. Singh U, Yadav S, Mehrotra S, Natu SM, Kumari K, Yadav YS.Serum lipid profile in early pregnancy as a predictor of preeclampsia. Int J. Med. Res Rev.2013; 1(2): 56-62.

20. Dr. Amit D.Sonagra et al.study of serum lipid profile in normal pregnancy. Int. $\mathrm{j}$ of Biotechnology and Biochemistry.2017; 13(2): 175-182.

Source of Support: The author(s) received no financial support for the research, authorship, and/or publication of this article.

Conflict of Interest: The author(s) declared no potential conflicts of interest with respect to the research, authorship, and/or publication of this article.

For any question relates to this article, please reach us at: editor@globalresearchonline.net New manuscripts for publication can be submitted at: submit@globalresearchonline.net and submit_ijpsrr@rediffmail.com 